\title{
Molar Incisor Hypomineralization (MIH): Literature Review and Case Report
}

\author{
Lorena Ribeiro Aguiar Trévia', Viviane Arruda de Castro', Lídia Audrey Rocha Valadas ${ }^{2 *}$, Celiane Mary Carneiro Tapety', Mirella de Sousa \\ Pereira $^{1,3}$, Francineudo Oliveira Chagas ${ }^{2}$, Camila Costa Dias ${ }^{1,3}$, Analice Mendes Barreto Fernandes ${ }^{2}$, Patrícia Leal Dantas Lobo ${ }^{1,2}$ \\ 'School of Dentistry, Federal University of Ceara, Sobral -CE, BRAZIL. \\ ${ }^{2}$ School of Dentistry, Federal University of Ceara, Fortaleza -CE, BRAZIL. \\ ${ }^{3}$ School of Dentistry, Unifametro, Fortaleza -CE, BRAZIL.
}

\begin{abstract}
Molar Incisor Hypomineralization (MIH) is a systemic defect on dental enamel, where the altered tissue may assume white, yellow or brown coloration, with a clear demarcation between the defect and the surrounding normal enamel. The etiologies have not been fully defined and early diagnosis is extremely important, since it can occur rapidly disintegrating dental structure, causing acute symptoms and making treatment difficult. Management of $\mathrm{MIH}$ is challenging, since the clinical appearance and individual need for treatment vary widely. To perform a literature review about $\mathrm{MIH}$, highlighting the characteristics of the pathology, etiological factors, diagnosis and treatment, as well as reporting conduct used in a clinical case. A patient, 10 years old, male, norm systemic, attended at the Pedodontic Clinic, at the Federal University of Ceará-Sobral, in Brazil, was searching for dental care treatment. At the clinical examination, it was observed that the patient had an open bite and was a mouth breather. After radiographic taking and visual inspection, the clinical diagnosis of $\mathrm{MIH}$ was reached. The treatment plan was established, which consisted in definitive resin restoration composed of elements $16,26,36$ and 46 , for later orthodontic
\end{abstract}

intervention. In the second treatment session, restoration was performed in composite resin of dental element 36 . The restoration was performed with Resin Composite Opallis (A3), incrementally. Posterior finishing and occlusal adjustment were performed. Although the etiology is still uncertain, it is important to establish a correct and early diagnosis, so that the most appropriate treatment can be instituted, depending of the severity. Key words: Tooth Demineralization, Etiology, Odontopediatric, Molar Incisor, Hypomineralization.

\section{Correspondence}

Dr. Lídia Audrey Rocha Valadas,

School of Dentistry, Federal University of Ceara, Sobral, Benfica, Fortaleza - CE, 60020-181, BRAZIL.

Phone: +55 8532667877

Email: lidiavaladas@hotmail.com

DOI: 10.5530/jyp.2020.12.37

\section{INTRODUCTION}

Incisor Molar Hypomineralization (MIH) is a defect in tooth enamel of systemic origin, where the altered enamel may take on a white, yellow or brown color, with a clear demarcation between the defect and the surrounding normal enamel. ${ }^{1}$ The enamel defect usually affects a or more permanent molars, with the incisors being frequently the most exposed dental elements, however the defects presented are less severe compared to the molars. ${ }^{2,3}$

There are no conclusive data regarding the etiology of these changes, however the defects observed in the enamel are the result of a variety of environmental factors that act at the systemic level and they may be acting in the prenatal, perinatal and childhood periods. ${ }^{4,5}$ The disorders may involve respiratory diseases, perinatal complications, low birth weight associated with lack of oxygen (hypoxia to ameloblasts), under nutrition, calcium and phosphate metabolic disorders and frequent childhood illnesses with a history of high fever. Some suggest that exposure to dioxin may increase the risk of MIH..$^{1,6,7}$

The dental enamel of teeth affected by $\mathrm{MIH}$ is fragile and can fracture easily, due to less hardness and elasticity modulus, in addition to the presence of disorganized and weakly attached prisms, making the enamel porous, which favors greater microbial proliferation and consequently, whether or not associated with other factors, the establishment of caries disease. There is sensitivity, in most cases, to cold, heat or mechanical trauma and brushing is usually painful, which makes the child avoid it. ${ }^{1,2,7}$
Clinically, the enamel is soft and porous. The demarcated opacities are brownish yellow and have clear and distinct edges from the adjacent normal enamel. One of the typical characteristics is its asymmetrical location, affecting mainly the $2 / 3$ occlusal of the crown, both in the molars and in the incisors and the enamel of one molar may be seriously affected while that of the contralateral can be clinically healthy or with small dimension. The severity and extent of the lesion vary according to the individual, which directly interferes with the type of treatment to be instituted..$^{5,6}$

The purpose of this article is to report on the clinical approach to the molar-incisor hypomineralization syndrome, also presenting the approach used in a clinical case.

\section{Clinical Case}

A patient, 10 years old, male, norm systemic, looking for dental care was attended at the Pedodontic Clinic of the Dentistry Course at the Federal University of Ceará-Sobral, Upon clinical examination, it was observed that the patient had an open bite and was a mouth breather. The intra-oral examination revealed the presence of calculus, biofilm and lesions located on the occlusal surface of the first four permanent molars, which are brownish yellow in color. During the initial clinical prophylaxis protocol, the patient complained of great sensitivity in the dental elements 16, 26, 36 and 46. After radiographic examination and visual inspection, the clinical diagnosis of MIH was 
reached. After scraping, oral hygiene instruction and supervised brushing, a treatment plan was established, which consisted of definitive restoration in resin composed of elements 16, 26, 36 and 46, for later orthodontic intervention. In the second treatment session, the composite resin restoration of the dental element 36 was performed.

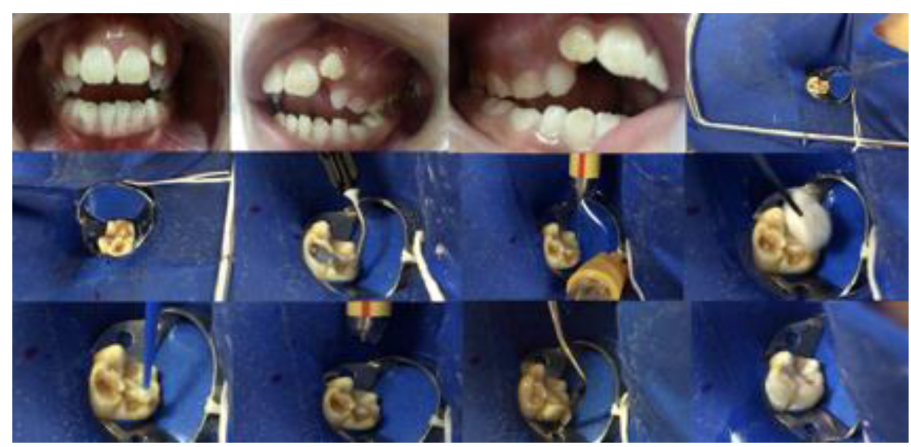

Sequence of the clinical case: Figures 1, 2 and 3: Aspect of the dental elements; Figures 4 and 5: Absolute isolation; Figure 6: 37\% acid conditioning for 30 sec; Figure 7: Washing the acid for 30 sec; Figure 8: Drying cotton ball; Figure 9: Light-curing adhesive application; Figure 10: Air jet application; Figure 11: Insertion of resinincrements; Figure 12: Final appearance after initialfinishing.

Topical anesthesia, blocking anesthesia of the lower alveolar nerve (3\% lidocaine), absolute isolation (Figure 2), conditioning with 37\% phosphoric acid for $30 \mathrm{sec}$ (Figure 3), washing of the acid for $30 \mathrm{sec}$ (Figure 4), removing excess water with absorbent paper (Figure 5), rigorous application of the conventional two-step adhesive (Figure 6), followed by air jets (Figure 7), light and constant, for solvent evaporation and then light curing for $40 \mathrm{sec}$. The restoration was carried out with Opallis Composite Resin (A3), incrementally (Figure 9). Subsequently, finishing and occlusal adjustment were performed (Figure 10).

\section{DISCUSSION}

According to Salanitri and Seow. ${ }^{8}$ the enamel hypomineralization is a qualitative deficiency of the enamel that can present itself as changes in its translucency or opacity, which can be diffuse or demarcated and white, yellow or brown. Diffuse opacifications are considered to be associated with the group of teeth that were undergoing enamel maturation at the time that a systemic intercourse occurred. According to Garg et al. ${ }^{9}$ opacities are generally limited to the incisal or crown cusp, rarely involving the cervical third, as in the case of the reported patient. The enamel has aprismatic layers with focal holes, being soft and porous, which can cause a rapid progression of caries. In addition, the patient may be hypersensitive and difficult to anesthetize. More complex MIH may present pulp involvement, due to the presence of larger interprismatic spaces that allows the diffusion of bacteria through the dentin more easily and can affect the pulp in a chronic way, resulting in chronic inflammation of the pulp..$^{10}$

Silva et al. ${ }^{11}$ and Vieira, Kup ${ }^{12}$ believe that the severity of incisor molar hypomineralization (MIH) can vary widely. It ranges from mild opacities to post-eruptive rupture. It can be asymmetrical, but if a permanent molar is severely affected, the contralateral molar is more likely to be affected. In the affected incisors, the severity of hypomineralization is generally less than that of the affected molars, a characteristic perceived in the treated case.

In addition, studies have already shown that conditions that affect the $\mathrm{pH}$ of the enamel matrix, that is, respiratory acidosis and abnormal oxygen levels resulting from hypoventilation in various respiratory diseases, inhibit the action of proteolytic enzymes and the development of crystalline hydroxyapatite, resulting in enamel hypomineralization. The lack of calcium phosphate in the area of crystallites can result in reduced calcium deposits and a lower proportion of calcium / phosphorus leading again to the enamel hypomineralization. Maternal pyrexia has beenexperimentallyshowntohaveadetrimentalinfluenceonamelogenesis, from ameloblastic dysfunction to complete cell degeneration. In the case of maternal diabetes, hypocalcemia in the mother and problems with oxygen scarcity for the baby can result in enamel hypomineralization. Prenatal conditions such as prolonged maternal nausea and vomiting compromisefluidsandelectrolytes, aswellasnutritionalstatus, occasionally leading to fetal biochemical disturbance. The use of spasmolytic medication with myometrium can produce side effects, such as nausea, vomiting and fetal hypocalcemia, which can again interrupt amelogenesis. Fluoride is believed to affect the formation of enamel crystals mainly during the maturation stage, inducing defects described as diffuse opacities. $^{4-6}$ Perinatal medical conditions appear to be associated with hypocalcemia and hypoxia.- ${ }^{4-6,13}$ In view of this, Faturi carried out a systematic review with meta-analysis, since MIH is a complex alteration in which systemic and genetic factors act together for its development, assessing the association between prenatal, perinatal and postnatal exposures. with $\mathrm{MIH} .^{14}$

According to Seow, ${ }^{15}$ etiological factors for MIH are suggestive to be essentially the same as those known for enamel hypoplasia in permanent dentition, where malnutrition, common childhood diseases, including smallpox, otitis media, respiratory and urinary tract infections and constant use of antibiotics such as amoxicillin. Although environmental toxins, such as dioxins, have also been implicated in the etiology of $\mathrm{MIH}$, this hypothesis has been questioned in a controlled study.

According to Garg et al. ${ }^{9}$ teeth with defects in enamel development may present in a similar way, regardless of aetiology and defects in the development of enamel hypoplasia can be confused with MIH. Enamel hypoplasia is a quantitative defect associated with reduced localized enamel thickness while hypomineralization is a qualitative defect that affects the translucency of the enamel.

In a child with a high rate of caries, MIH can be masked by extensive caries or restorations. However, in hypoplasia, the edges of the defective enamel are smooth, while in the emptying of the post-eruptive enamel the edges of the normal enamel are irregular. MIH can also be confused with fluorosis, however, the opacities of fluorosis enamel are diffuse, in contrast to the well-demarcated borders of the hypomineralized enamel seen in MIH. In addition, fluorinated enamel is resistant to caries. In comparison with the enamel affected by MIH affected by caries. Furthermore, the difference between MIH and imperfect amelogenesis is one of definition. In the latter, all teeth are affected and can be detected pre-eruptively on the radiograph. Generally, the first permanent molars affected with $\mathrm{MIH}$ are asymmetric, as can be seen in the present case. ${ }^{4-6,9}$ Elhennawy et al. ${ }^{16}$, Seow et al. ${ }^{15}$ and Salanitri and Seow. ${ }^{8}$ corroborate that the treatment conducts to be instituted can be management of hypersensitivity or pain through the use of desensitizers; restorative treatments, using composite resin, glass ionomer cement or indirect restorations, extraction with or without subsequent orthodontic alignment of adjacent teeth. Neutral sodium fluoride gel or varnishes; amorphous casein-calcium phosphate (CPP-ACP). Changes in eating habits, daily brushing, topical application of fluoride, rinses, stainless steel crowns.

According to Elhennawy et al. ${ }^{16}$ for mild cases, as well as for aesthetic purposes (mainly in incisors), microabrasion can be an option, while the loss of associated substance was significant in severe cases. 


\section{CONCLUSION}

It was possible to observe through the studied literature, that although the etiology is still uncertain, multifactorial and not yet fully defined, it is important to establish an accurate and early diagnosis, in order to establish the most appropriate treatment for the degree of severity of $\mathrm{MIH}$, as in the present clinical case.

It is important that the patient with this condition, thus having a high risk of caries, periodically visits the dentist and has an efficient oral hygiene.

\section{REFERENCES}

1. Pordeus IA, Paiva SM. Odontopediatria. $1^{\text {st }}$ ed. Artes Médicas: Riode Janeiro. 2014.

2. Neville BW. Patologia Oral e Maxilofacial. $4^{\text {th }}$ ed. Elsevier: São Paulo. 2011.

3. Zhao D, Dong B, Yu D, Ren $Q$, Sun Y. The prevalence of molar incisor hypomineralization: Evidence from 70 studies. Int J Paediatr Dent. 2018;28(2):170-9.

4. Crombie F, Manton D, Kilpatrick N. Aetiology of molar-incisor hypomineralization: A critical review. Int J Pediatric Dent. 2009;19(2):73-83.

5. Fernandes AS, Mesquita $P$, Vinhas L. Hipomineralização incisivo-molar: Uma revisão da literatura. Rev Portug Estomatol Med Dent Cir Maxilofac. 2012;53(4):258-62.

6. Basso AP, Ruschel HC, Gatterman A, Ardenghi TM. Hipomineralização molar- incisivo. Rev Odonto Cienc. 2007;22(58):371-6.

7. Schwendicke F, Elhennawy K, Reda S, Bekes K, Manton DJ, Krois J. Global burden of molar incisor hypomineralization. J Dent. 2018;68:10-8.

8. Salanitri S, Seow WK. Developmental enamel defects in the primary dentition: Aetiology and clinical management. Aust Dent J. 2013;58(2):133-40.

9. Garg N, Jain AK, Saha S, Singh J. Essentiality of early diagnosis of molar incisor hypomineralization in children and review of its clinical presentation, etiology and management. Int J ClinPediat Dent. 2012;5(3):190-6.

10. Garot E, Manton D, Rouas P. Peripartum events and molar-incisor hypomineralisation $(\mathrm{MIH})$ amongst young patients in southwest France. Eur Arch Paediatr Dent. 2016;17(4):245-50.

11. Silva MJ, Scurrah KJ, Craig JM, Manton DJ, Kilpatrick N. Etiology of molar incisor hypomineralization: A systematic review. Com Dent Oral Epidemiol. 2016;44(4):342-53.

12. Vieira AR, Kup E. On the Etiology of Molar-Incisor Hypomineralization. Caries Res. 2016;50(2):166-9.

13. Lima $M$ andrade $M$, Dantas-Neta NB, et al. Epidemiologic study of molarincisor hypomineralization in schoolchildren in Northeastern Brazil. PediatrDent. 2015;37(7):513-9.

14. Fatturi AL, Wambier LM, Chibinski AC, Assunção LRDS, Brancher JA, Reis A et al. A systematic review and meta-analysis of systemic exposure associated with molar incisor hypomineralization. Community Dent Oral Epidemiol. 2019;47(5):407-15

15. Seow WK. Developmental defects of enamel and dentine: Challenges for basic science research and clinical management. Aust Dent J. 2014;59(1):143-54.

16. Elhennawy K, Schwendicke F. Managing molar-incisor hypomineralization: A systematic review. J Dent. 2016;55(1):16-24

Article History: Submission Date : 10-04-2020; Revised Date : 28-04-2020; Acceptance Date : 19-05-2020.

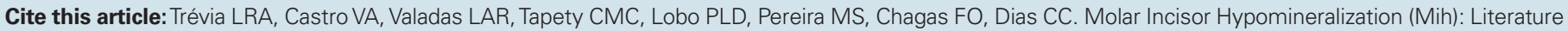
Review and Case Report. J Young Pharm. 2020;12(2):182-4. 